\title{
Steroid hormones regulate sperm-oviduct interactions in the bovine
}

\author{
Julie Lamy , Emilie Corbin, Marie-Claire Blache , Anastasiia S Garanina ${ }^{2,3}$, Rustem Uzbekov², \\ Pascal Mermillod ${ }^{1}$ and Marie Saint-Dizier ${ }^{1,5}$ \\ ${ }^{1}$ Physiologie de la Reproduction et des Comportements (PRC), UMR85, INRA, CNRS, UFR, IFCE, Nouzilly, France, \\ ${ }^{2}$ Université François Rabelais de Tours, Département des Microscopies, Tours, France, ${ }^{3}$ NUST MISiS, Leninskiy \\ prospekt 4, Moscow, Russia, ${ }^{4}$ Faculty of Bioengineering and Bioinformatics, Moscow State University, Moscow, \\ Russia and ${ }^{5}$ Université François Rabelais de Tours, UFR Sciences et Techniques, Tours, France
}

Correspondence should be addressed to M Saint-Dizier; Email: marie.saint-dizier@univ-tours.fr

\begin{abstract}
After insemination in the cow, a sperm reservoir is formed within the oviducts, allowing the storage and then progressive release of spermatozoa toward the ovulated oocyte. In order to investigate the hormonal regulation of these events in vitro, the ovarian steroids $17 \beta$-estradiol (E2) and progesterone (P4) were added at various concentrations to monolayers of bovine oviduct epithelial cells (BOEC) before or during co-incubation with spermatozoa. Main findings demonstrate that (1) a 18-h pretreatment of BOEC with $100 \mathrm{pg} / \mathrm{mL}$ and $100 \mathrm{ng} / \mathrm{mL}$ of E2 decreased by $25 \%$ the ability of BOEC to bind spermatozoa after $10 \mathrm{~min}$, and for the highest dose of E2, 60 min of co-incubation; (2) P4 at concentrations of 10, 100 and $1000 \mathrm{ng} / \mathrm{mL}$ induced the release within $60 \mathrm{~min}$ of $32-47 \%$ of bound spermatozoa from BOEC; this sperm-releasing effect was maintained after a 18-h pretreatment of BOEC with $100 \mathrm{pg} / \mathrm{mL}$ of E2; (3) E2 in concentrations above $100 \mathrm{pg} / \mathrm{mL}$ inhibited the releasing effect of P4 on bound sperm in a dose-dependent manner;

(4) spermatozoa bound to BOEC, then released from BOEC by the action of P4-induced higher cleavage and blastocyst rates after in vitro fertilization than the control group. These results support the hypothesis that the dynamic changes in steroid hormones around the time of ovulation regulate the formation of the sperm reservoir and the timed delivery of capacitated spermatozoa to the site of fertilization.
\end{abstract}

Reproduction (2017) 154 497-508

\section{Introduction}

After mating or insemination in mammals, only a limited number of spermatozoa enter the oviducts, where many of them soon bind to the oviductal epithelium in the so-called 'functional sperm reservoir' (Suarez 2016). In the bovine, the sperm reservoir is formed over a period of $8-12 \mathrm{~h}$ after insemination and spermatozoa can be stored for hours up to days before they are assumed to be released as capacitated cells and move toward the site of fertilization around the time of ovulation (Hunter \& Wilmut 1984, Hung \& Suarez 2010).

These interactions between oviduct epithelial cells (OEC) and spermatozoa are believed to play an important role in sperm selection in a number of species including the bovine. Only spermatozoa with intact plasma membrane and acrosome (Thomas et al. 1994, Lefebvre \& Suarez 1996, Gualtieri \& Talevi 2000), superior morphology and normal chromatin structure (Ellington et al. 1999a) can bind to OEC in vitro. The attachment to OEC was found to have beneficial effects on sperm motility, survival and fertilizing ability
(Ellington et al. 1991, Pollard et al. 1991, Gualtieri \& Talevi 2000, 2003). Furthermore, the ability of sperm to bind to OEC in vitro appears to be correlated with in vivo fertility in bulls (De pauw et al. 2002), stallions (Ellington et al. 1999b) and pigs (Waberski et al. 2005).

A synchronized sperm binding followed by the release from the oviductal reservoir is necessary to allow capacitated spermatozoa to be present around the oocyte at the time of ovulation. The release of bovine spermatozoa from OEC monolayers can be induced in vitro by heparin, sulfated heparin-like glycoconjugates and the endocannabinoid anandamide (Talevi \& Gualtieri 2001, 2010, Gervasi et al. 2009). However, very little is known about the regulation of these events in vivo. The formation of the sperm reservoir occurs at the end of the follicular phase of the estrous cycle in parallel with high concentrations of $17 \beta$-estradiol (E2) and low concentrations of progesterone (P4) in the circulating plasma (Glencross et al. 1973) and locally within the oviduct (Lamy et al. 2016). By contrast, the release of spermatozoa from the sperm reservoir occurs around the time of ovulation, in parallel with decreasing 
concentrations of E2 and increasing concentrations of P4 (Glencross et al. 1973, Lamy et al. 2016). Stimulating roles of $\mathrm{P} 4$ at various doses were found in mammalian sperm capacitation, hyperactivated motility, acrosome reaction and chemical guidance (Baldi et al. 2009, Guidobaldi et al. 2012, Fujinoki et al. 2016) while E2 was reported to inhibit P4-induced acrosome reaction (Vigil et al. 2008, Baldi et al. 2009) and sperm hyperactivation (Fujinoki 2010). However, the potential roles played by the periovulatry dynamic changes in $\mathrm{P} 4$ and $\mathrm{E} 2$ in the regulation of sperm-oviduct interactions are poorly known.

In the porcine, the binding of spermatozoa to oviductal explants in vitro was not affected by the stage of the estrous cycle but was increased by addition of $70 \mathrm{pg} / \mathrm{mL}$ of E2 to the co-culture medium (Suarez et al. 1991). On the other hand, the pretreatment of porcine oviduct explants with P4 but not E2 modulated the ability of epithelial cells to bind spermatozoa (Bureau et al. 2002). Moreover, the experimental microinjection of exogenous P4 or steroid-rich preovulatory follicular fluid into the oviductal wall in sows increased considerably the number of spermatozoa around the oocyte and the polyspermy compared to control animals (Hunter 1972, Hunter et al. 1999), leading to the hypothesis that P4 might trigger sperm release from the porcine oviductal reservoir (Hunter 2008). However, the very low concentration of $\mathrm{P} 4$ (around $0.1 \mathrm{ng} / \mathrm{mL}$ ) in the porcine oviductal fluid prior to and after ovulation (Brussow et al. 2008) compared to the concentrations tested in the previous studies $(100 \mathrm{ng} / \mathrm{mL}$ in vitro and $1 \mathrm{mg} / \mathrm{animal}$ in vivo) do not allow to conclude on such a role. In the bovine, data on the regulation of the sperm reservoir by steroid hormones are scarce and inconsistent. In vitro, the number of spermatozoa that bound to bovine oviductal explants was higher before than after ovulation (Sostaric et al. 2008) or was not affected by the stage of the cycle (Lefebvre et al. 1995). We reported earlier a consistent rise in $\mathrm{P} 4$ concentrations (from 6 to $57 \mathrm{ng} / \mathrm{mL}$ ) in parallel with a decrease in E2 concentrations (from 290 to $118 \mathrm{pg} / \mathrm{mL}$ ) in the bovine oviductal fluid ipsilateral to the side of ovulation from the pre- to the postovulatory stage of the estrous cycle (Lamy et al. 2016). We hypothesized that P4 and E2 may regulate the attachment to and release from the sperm reservoir and select by this way a subpopulation of spermatozoa with high fertilizing competence.

Thus, the objectives of this study were to evaluate the effects of P4 and E2 at various concentrations on (1) the ability of BOEC to bind spermatozoa; (2) the release of bound spermatozoa from BOEC and (3) to investigate the fertilizing ability of spermatozoa bound to and subsequently released from BOEC.

\section{Materials and methods}

Unless specified, all chemicals were purchased from Sigma-Aldrich.

Reproduction (2017) 154 497-508

\section{Bovine oviductal epithelial cell culture}

The process of primary cell culture used in this study was already described and validated, indicating a high rate of epithelial cells (ciliated and secretory) expressing cytokeratin and showing an epithelial type ultrastructure under electron microscope (Van Lagendonckt et al. 1995). Briefly, bovine oviducts were collected from a local slaughterhouse and transported at $37^{\circ} \mathrm{C}$ to the laboratory within 2-h post-mortem and processed immediately as follows. According to the morphology of ovaries and corpus luteum (Ireland et al. 1980), only oviducts at pre- or postovulatory stage were used. Both oviducts from a cow were cleaned from surrounding tissues and mucosae were mechanically expelled from the whole oviducts by gentle scraping with a sterile glass slide. Bovine OEC (BOEC) were then washed three times $10 \mathrm{~min}$ by sedimentation with HEPES-buffered tissue culture medium-199 (TCM199). The resulting cellular pellet was diluted in $10 \mathrm{~mL}$ of TCM199 supplemented with $10 \%$ heat-treated fetal calf serum (FCS) and $80 \mu \mathrm{g} / \mathrm{mL}$ gentamycin before seeding in a Lab-Tek II Chamber Slide system (Nunc, Roskidle, Denmark) and placed in a humidified atmosphere with $5 \% \mathrm{CO}_{2}$ at $38.8^{\circ} \mathrm{C}$. The medium was renewed after $48 \mathrm{~h}$, and then half-renewed every $48 \mathrm{~h}$ until cell confluence (7-8 days).

\section{Sperm preparation and co-incubation with BOEC}

A pool of frozen semen from three bulls (Bos taurus, $0.25-\mathrm{mL}$ straws, approximately $20 \times 10^{6}$ spermatozoa/straw) was used in all experiments. Straws were thawed in a water bath at $37^{\circ} \mathrm{C}$ for one minute and then washed on a discontinuous Percoll (GE Healthcare Life Sciences) density gradient (45/90\%). The sperm pellet was washed and stained at the same time in $5 \mathrm{~mL}$ of STL-medium (Tyrode medium supplemented with $25 \mathrm{mM}$ bicarbonate, $10 \mathrm{mM}$ lactate, $100 \mathrm{IU} / \mathrm{mL}$ penicillin, $100 \mu \mathrm{g} /$ $\mathrm{mL}$ streptomycin and $2.4 \mathrm{mg} / \mathrm{mL}$ HEPES) containing $10 \mu \mathrm{g} /$ $\mathrm{mL}$ of the blue DNA dye Hoechst 33342 at $37^{\circ} \mathrm{C}$ and then centrifuged at $100 \mathrm{~g}$ for $10 \mathrm{~min}$. The final sperm pellet was resuspended in IVF-medium (Tyrode medium supplemented with $25 \mathrm{mM}$ bicarbonate, $10 \mathrm{mM}$ lactate, $1 \mathrm{mM}$ pyruvate, $6 \mathrm{mg} / \mathrm{mL}$ fatty acid free bovine serum albumin, $100 \mathrm{IU} / \mathrm{mL}$ penicillin and $100 \mu \mathrm{g} / \mathrm{mL}$ streptomycin) and the concentration of spermatozoa was determined with a Thoma cell. Before being inseminated with spermatozoa, BOEC at confluence were washed once with IVF-medium and then incubated for 5 minutes with $5 \mu \mathrm{M}$ of the fluorescent red DNA dye DRAQ5 (Deep Red Anthraquinone 5; ThermoScientific), then washed again with the same medium. All experiments of sperm-BOEC co-incubation were performed in IVF-medium at $38.8^{\circ} \mathrm{C}$ in a humidified atmosphere with $5 \% \mathrm{CO}_{2}$.

\section{Quantification of bound spermatozoa}

At the end of co-incubation, BOEC were vigorously washed three times with IVF-medium in order to eliminate unbound and slightly attached spermatozoa. BOEC were then fixed in $2.5 \%$ glutaraldehyde in PBS for one night at room temperature, and then rinsed in PBS and mounted under a coverslip. Slides were observed with a $20 \times$ NA 0.5 objective, using a laserscanning confocal microscope (LSM780, Zeiss, Oberkochen, 
Germany) coupled with a spectral imaging detector. The entire spectrum of fluorophores in the specimen was first gathered and then linearly unmixed. The linear unmixing was performed on Zen 2011 software (Carl Zeiss) with the 'Online fingerprinting' mode. The excitation wavelengths 405 and 633 were used for Hoechst and DRAQ5, respectively. For each experimental condition, the number of BOEC and bound spermatozoa was automatically determined by analyzing 10 randomly chosen fields of $0.18 \mathrm{~mm}^{2}$ using the image processing software Fiji (Schindelin et al. 2012). This software surrounded all counted cells with a thin white line. The counting of all BOEC and sperm cells by the software was then checked visually. Numbers of bound spermatozoa were finally reported to 100 BOEC for each condition.

\section{Correlative scanning-transmission electron microscopy}

Interactions between spermatozoa and BOEC were observed using the correlative scanning/transmission electron microscopy (CSTEM) method previously reported for observations of cell-virus interactions (Burlaud-Gaillard et al. 2014). A preliminary study was conducted to determine the time course of sperm binding to BOEC: the mean number of bound sperm per 100 BOEC increased during the first 30 min of co-incubation, and then reached a plateau that was maintained for at least $120 \mathrm{~min}$ (data not shown). BOEC were co-incubated for $30 \mathrm{~min}$ with spermatozoa at a final concentration of $0.5 \times 10^{6} / \mathrm{mL}$ as described previously. Samples were fixed with $4 \%$ paraformaldehyde and $1 \%$ glutaraldehyde in $0.1 \mathrm{M}$ phosphate buffer ( $\mathrm{pH} 7.4$ ) for $48 \mathrm{~h}$ and post-fixed with $2 \%$ osmium tetroxide in $0.15 \mathrm{M}$ phosphate buffer $(4 \%$ osmium solution was diluted with $0.3 \mathrm{M}$ phosphate buffer) for $1 \mathrm{~h}$. Samples were washed in PBS $(10 \mathrm{~min})$ and water $(3 \times 10 \mathrm{~min})$, dehydrated in a graded series of ethanol solutions then incubated for $3 \mathrm{~h}$ in hexamethyldisilazane (HMDS) diluted at $50 \%$ in ethanol, then in pure HMDS for $1 \mathrm{~h}$ and were dried on air in a second HMDS solution. For easy orientation of samples, a coordinate grid was applied to the Lab-Tek slide surface. Dry samples were sprinkled onto carbon disks and coated with $4 \mathrm{~nm}$ of palladium with a GATAN PECS 682 apparatus (Pleasanton, USA) before observation under a Zeiss Ultra plus FEG-S.E.M. scanning electron microscope (Zeiss). Zones of interest were photographed at various magnifications from $30 \times$ to $8000 \times$. Lab-Tek slides were then separated from carbon disks with a scalpel and incubated in a mixture of absolute ethanol and EPON (3:1 in volume) for $3 \mathrm{~h}$ with closed caps and for $16 \mathrm{~h}$ with open caps and then transferred in pure EPON, which was allowed to polymerize for $24 \mathrm{~h}$ at $37^{\circ} \mathrm{C}$ and $48 \mathrm{~h}$ at $60^{\circ} \mathrm{C}$. After polymerization, the Lab-Tek slides were separated from the EPON block by scalpel and forceps. Cells were found using coordinates on the grid and previous S.E.M. photos under a Zeiss Stemi 2000c stereo microscope and Nikon Eclipse 80i microscope connected with Nikon DS-Vi1 camera driven by NIS-ELEMENTS D 4.4 (Nikon) software. Semi-thin $(0.5 \mu \mathrm{m})$ and ultra-thin $(70 \mathrm{~nm})$ sections were made with a Leica Ultracut UCT ultramicrotome (Wetzlar, Germany) in a plane perpendicular to cell cultivation surface. Semithin sections were stained with toluidine blue $\left(30 \mathrm{~s}\right.$ at $\left.60^{\circ} \mathrm{C}\right)$ and used for more precise identification of section level.
When areas of interest were at 3 microns from the edge of the block, serial ultra-thin sections were made, placed on EM one-slot grids coated with Formvar film and stained with $5 \%$ uranyl acetate for $20 \mathrm{~min}$. The sections were then observed at $100 \mathrm{kV}$ with a Jeol 1011 transmission electron microscope (Tokyo, Japan) connected to a Gatan digital camera driven by Digital Micrograph software (Gatan, Pleasanton, CA) for image acquisition and analysis.

\section{Hormonal treatments}

The general design of treatments applied to BOEC before and during sperm co-incubation is summarized in Fig. 1. For the following Experiments 1-4, BOEC were co-incubated with spermatozoa at a final concentration of $0.5 \times 10^{6} / \mathrm{mL}$. In all experiments, working solutions of $\mathrm{P} 4$ and $\mathrm{E} 2$ were diluted in absolute ethanol and added at a final concentration of $0.5 \%$ ethanol in culture medium. A vehicle control containing an equivalent amount of ethanol had no effect on the time course of sperm binding (data not shown).

Experiment 1 was designed to study the effects of a pretreatment of BOEC with E2 or P4 on sperm binding. BOEC monolayers were pretreated for $18 \mathrm{~h}$ with $\mathrm{E} 2$ at $1,100 \mathrm{pg} / \mathrm{mL}$ or $100 \mathrm{ng} / \mathrm{mL}$ or P4 at 10,100 or $1000 \mathrm{ng} / \mathrm{mL}$. According to the concentrations of E2 and P4 previously measured in the bovine oviductal fluid in the periovulatory period (Lamy et al. 2016), concentrations of $100 \mathrm{pg} / \mathrm{mL}$ of $\mathrm{E} 2$ and of 10 and $100 \mathrm{ng} / \mathrm{mL}$ of P4 were considered to be physiological. Control samples were pretreated with an equivalent concentration of vehicle. Cells were then rinsed and co-incubated with spermatozoa for 10 or $60 \mathrm{~min}$. After three washings to remove unbound spermatozoa, co-cultures were fixed for quantitative analysis of bound sperm as previously described.

Experiment 2 was designed to study the effects of E2 and $\mathrm{P} 4$ on sperm release from BOEC. BOEC monolayers were co-incubated with spermatozoa for $30 \mathrm{~min}$. After three washings to remove unbound spermatozoa, co-cultures were treated for $60 \mathrm{~min}$ with $\mathrm{E} 2$ at $1,100 \mathrm{pg} / \mathrm{mL}$ or $100 \mathrm{ng} / \mathrm{mL}$, or $\mathrm{P} 4$ at 10,100 or $1000 \mathrm{ng} / \mathrm{mL}$ or with heparin at $100 \mu \mathrm{g} / \mathrm{mL}$. This latter treatment was chosen as a positive control because heparin at $100 \mu \mathrm{g} / \mathrm{mL}$ was previously reported to induce the release of $\sim 100 \%$ of spermatozoa bound to BOEC monolayer within $1 \mathrm{~h}$ (Talevi \& Gualtieri 2001). Control samples were treated with an equivalent concentration of vehicle. After three washings to remove unbound spermatozoa, co-cultures were fixed for quantitative analysis of bound spermatozoa.

Experiment 3 was a partial combination of Experiments 1 and 2 using physiological concentrations of E2 and P4. BOEC monolayers were pretreated during $18 \mathrm{~h}$ with $\mathrm{E} 2$ at $100 \mathrm{pg} / \mathrm{mL}$, and then rinsed and co-incubated for $30 \mathrm{~min}$ with spermatozoa. After three washings to remove unbound spermatozoa, co-cultures were treated for $60 \mathrm{~min}$ with P4 at $100 \mathrm{ng} / \mathrm{mL}$. Control samples were treated with equivalent concentration of vehicle. After three washings to remove unbound spermatozoa, co-cultures were fixed for quantitative analysis of bound spermatozoa.

Experiment 4 was designed to study the effects of E2 on the P4-induced release of spermatozoa from BOEC. BOEC monolayers were co-incubated with spermatozoa for $30 \mathrm{~min}$. 


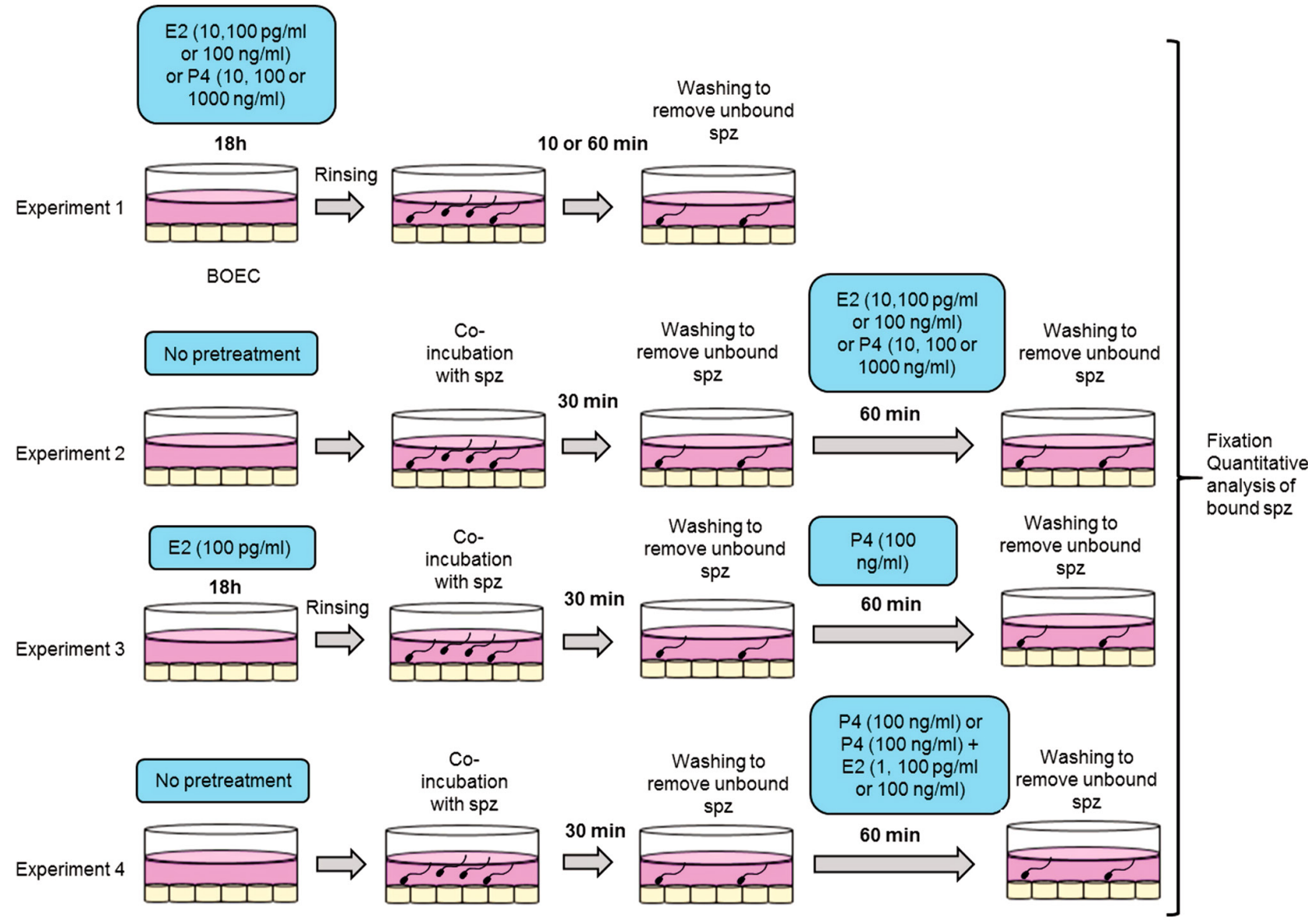

Figure 1 General design of hormonal treatments applied to BOEC monolayers before or during co-incubations with spermatozoa in Experiments 1-4. BOEC, Bovine oviductal epithelial cells; E2, 17ß-estradiol; P4, progesterone; spz, spermatozoa. See Materials and methods section for details.

After three washings to remove unbound spermatozoa, co-cultures were treated for $60 \mathrm{~min}$ with $\mathrm{P} 4$ at $100 \mathrm{ng} / \mathrm{mL}$ or a combination of $\mathrm{P} 4$ at $100 \mathrm{ng} / \mathrm{mL}$ with $\mathrm{E} 2$ at $1,100 \mathrm{pg} / \mathrm{mL}$ or $100 \mathrm{ng} / \mathrm{mL}$. Control samples were treated with an equivalent concentration of vehicle. After three washings to remove unbound spermatozoa, co-cultures were fixed for quantitative analysis of bound spermatozoa as described above.

All experiments were repeated 3-4 times.

\section{In vitro fertilization and embryo culture}

Bovine oocytes were collected and matured in vitro as previously described (Cordova et al. 2014). Bovine ovaries were collected at a local slaughterhouse and cumulus-oocyte complexes (COCs) were collected by aspirating follicles of $2-5 \mathrm{~mm}$ in diameter. COCs surrounded by several layers of compact cumulus cells were selected and washed three times in HEPES-buffered TCM199. Groups of 50 COCs were then transferred into four-well dishes (Nunc) and allowed to mature for $22 \mathrm{~h}$ in $500 \mu \mathrm{L}$ of TCM199 supplemented with EGF $(10 \mathrm{ng} / \mathrm{mL})$, IGF-1 $(19 \mathrm{ng} / \mathrm{mL})$, FGF $(2.2 \mathrm{ng} / \mathrm{mL})$, hCG $(5 \mathrm{IU} / \mathrm{mL})$, PMSG $(10 \mathrm{IU} / \mathrm{mL})$, insulin $(5 \mu \mathrm{g} / \mathrm{mL})$, transferrin $(5 \mu \mathrm{g} / \mathrm{mL})$, selenium $(5 \mathrm{ng} / \mathrm{mL})$, L-cystein $(90 \mu \mathrm{g} / \mathrm{mL})$, betamercaptoethanol $(0.1 \mathrm{mM})$, ascorbic acid $(75 \mu \mathrm{g} / \mathrm{mL})$, glycine
$(720 \mu \mathrm{g} / \mathrm{mL})$, glutamine $(0.1 \mathrm{mg} / \mathrm{mL})$ and pyruvate $(110 \mu \mathrm{g} /$ $\mathrm{mL}$ ) at $38.8^{\circ} \mathrm{C}$ in a humidified atmosphere with $5 \% \mathrm{CO}_{2}$. At the end of maturation, COC were washed three times in IVFmedium before being transferred in groups of 30-50 into fourwell dishes for insemination.

The general design of sperm treatments before IVF is summarized in Fig. 2. Spermatozoa and BOEC were prepared as described above except that Hoechst and DRAQ5 staining, respectively, were omitted. BOEC monolayers were co-incubated for $30 \mathrm{~min}$ with spermatozoa at a final concentration of $4 \times 10^{6}$ spermatozoa $/ \mathrm{mL}$ in twelve-well dishes (CytoOne, Starlab, Miltone Keynes, United Kingdom) containing $1 \mathrm{~mL}$ of IVF-medium per well. After co-incubation, BOEC were washed three times with IVF-medium: the cell supernatant and washing medium containing unbound spermatozoa in the presence of BOEC (BOEC-spz) were kept $\left(38.8^{\circ} \mathrm{C}, 5 \% \mathrm{CO}_{2}\right.$ in air). The release of bound sperm from BOEC was then induced by a treatment for 60 min with P4 at a final concentration of $100 \mathrm{ng} / \mathrm{mL}$. BOEC were then washed three times with IVF-medium: the cell supernatant and washing medium were kept to recover the P4-released sperm subpopulation (P4-BOEC-spz). To test the effects of P4 alone, spermatozoa incubated without BOEC in IVF-medium were treated with $100 \mathrm{ng} / \mathrm{mL}$ of P4 for $60 \mathrm{~min}$ (P4-spz). As controls, 


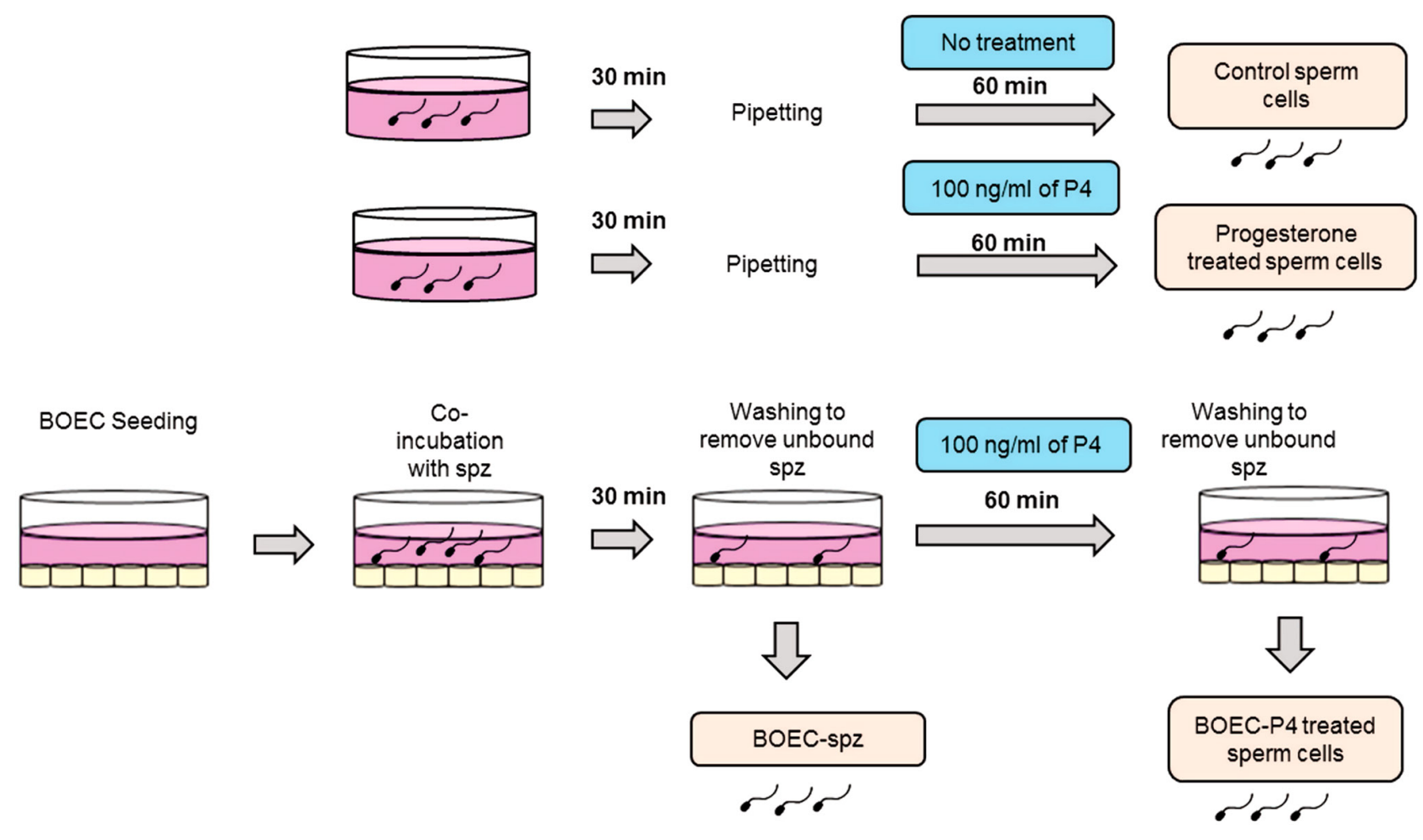

Figure 2 General design of sperm pretreatment before in vitro fertilization experiments. BOEC, Bovine oviductal epithelial cells; BOEC-spz, unbound sperm after 30 min of co-incubation with BOEC; BOEC-P4-spz, sperm bound to BOEC after 30 min of co-incubation then released by a 60 -min treatment with $100 \mathrm{ng} / \mathrm{mL}$ of P4; Control spz, sperm manipulated as other treated groups; P4, progesterone; P4-spz, sperm manipulated as other treated groups and treated with $100 \mathrm{ng} / \mathrm{mL}$ of P4 during $60 \mathrm{~min}$ before IVF. See Materials and methods section for details.

spermatozoa were thawed and prepared just before oocyte insemination as previously described (control with vehicle) or incubated at a final concentration of $4 \times 10^{6}$ spermatozoa/ $\mathrm{mL}$ in IVF-medium and manipulated by pipetting as other treated groups (control with vehicle and manipulation). The incubation of control with manipulation and P4-spz groups started at the same time as those co-incubated with BOEC. At the end of treatments, BOEC-spz, P4-BOEC-spz, P4-spz and control with manipulation were centrifuged for $10 \mathrm{~min}$ at $100 \mathrm{~g}$. Sperm pellets were pooled per condition and sperm concentrations determined with a Thoma cell. For IVF, sperm cells at a final concentration of $1 \times 10^{6} / \mathrm{mL}$ were co-incubated with in vitro-matured oocytes at $38.8^{\circ} \mathrm{C}$ in $500 \mu \mathrm{L}$ of IVFmedium containing $10 \mu \mathrm{g} / \mathrm{mL}$ heparin in a humidified atmosphere with $5 \% \mathrm{CO}_{2}$.

Twenty-two hours post insemination (pi), presumptive zygotes were washed three times in synthetic oviductal fluid (Holm et al. 1999) to remove cumulus cells and attached spermatozoa. Zygotes were then cultured in $25 \mu \mathrm{L}$ drops of SOF supplemented with 5\% heat-treated FCS and overlaid with $700 \mu \mathrm{L}$ of mineral oil. Zygotes were incubated for 8 days at $38.8^{\circ} \mathrm{C}$ in a humidified atmosphere containing $5 \% \mathrm{O}_{2}$, $5 \% \mathrm{CO}_{2}$ and $90 \% \mathrm{~N}_{2}$. Cleavage rates were determined on Day 2 pi. Blastocyst rates were determined on Days 7 and 8 pi as percentages of total number of COCs and total number of cleaved embryos.

\section{Statistical analysis}

Data were analyzed using the $\mathrm{R}$ software (version 3.2.3, tests of Foundation for Statistical Computing, Vienna, Austria). Data from Experiments 1-4 did not pass the tests for normality and homogeneity of variances (Shapiro-Wilk and Fligner-Killeen, respectively): the non-parametric KruskalWallis test was used followed by Dunn's test for multiple comparisons. In IVF experiments, the effects of treatment on cleavage and blastocyst rates were compared using chisquare analysis. The two control groups (control with and without manipulation) were not different and pooled for further analysis. Differences were considered statistically significant when $P<0.05$.

\section{Results}

\section{Observation of sperm-BOEC interactions}

CSTEM analysis showed that sperm heads with intact acrosome interacted with both cilia and microvilli at the apical surface of BOEC (Fig. 3). Close contacts were seen between epithelial cells and the whole bottom surface of sperm heads (Fig. 3B) or only the sperm rostral acrosomal region (Fig. $3 \mathrm{~B}$ and $\mathrm{D}$ ). 


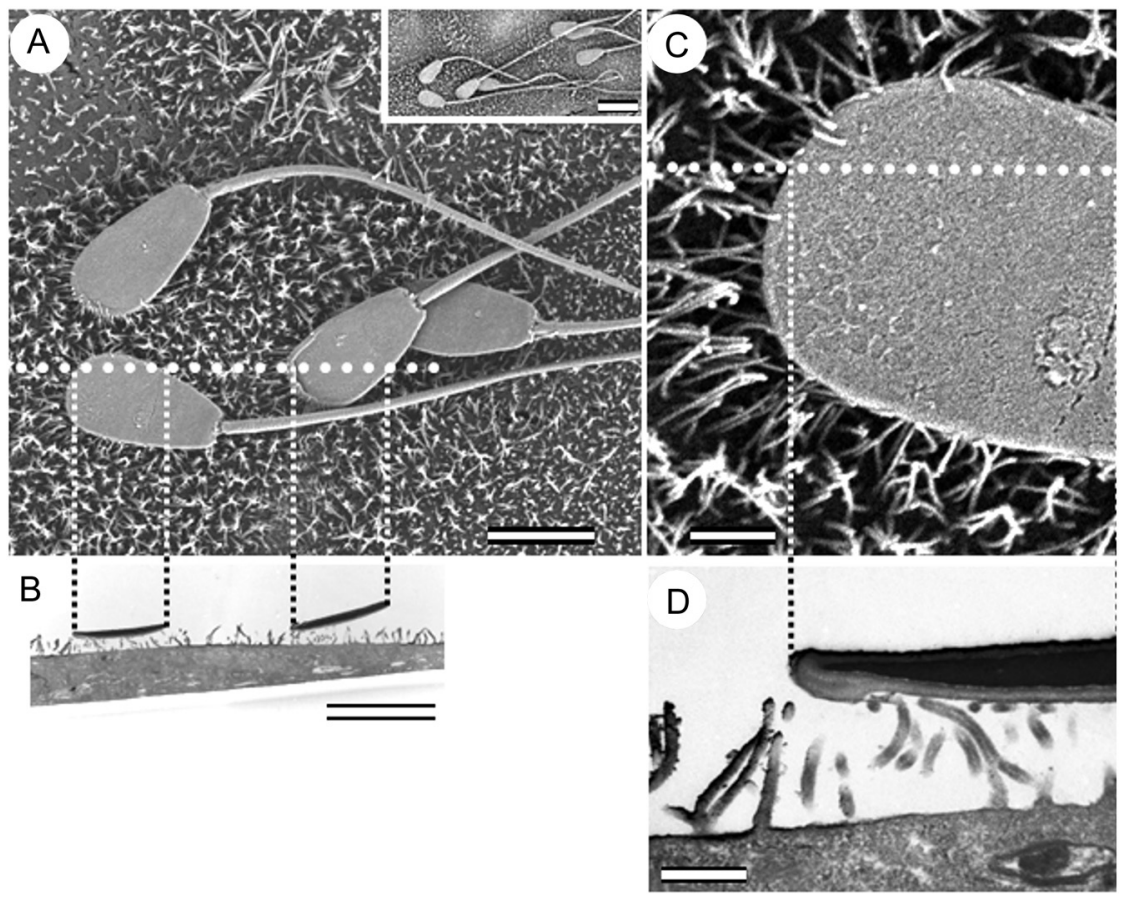

Figure 3 Observation of sperm-BOEC interactions by correlative scanning/ transmission electron microscopy. (A) Scanning electron micrograph of spermatozoa bound on BOEC microvilli; insert: sperm cells at small magnification; (B) TEM image of the same cells showing interactions between the whole bottom face (on the left) or the rostral acrosomal region (on the right) of the sperm head with microvilli; (C) S.E.M. image at high magnification of a sperm head bound to microvilli; (D) TEM image of the same sperm head, showing its bottom part interacting with BOEC microvilli. TEM sections were prepared in the plane perpendicular to cell cultivation surface: dotted lines in (A and C) show levels of section. Scale bars: $10 \mu \mathrm{m}$ (insert in $\mathrm{A}$ ); $5 \mu \mathrm{m}(\mathrm{A}$ and $\mathrm{B}) ; 1 \mu \mathrm{m}(\mathrm{C}$ and $\mathrm{D})$.

\section{Pretreatment of BOEC with E2 modified the kinetics of sperm binding}

In Experiment 1, a significant decrease by $25 \%$ in the mean number of bound sperm was observed after $10 \mathrm{~min}$ of co-incubation with BOEC pretreated with $100 \mathrm{pg} / \mathrm{mL}$ and $100 \mathrm{ng} / \mathrm{mL}$ of E2 $(P<0.05)$, and after $60 \mathrm{~min}$ of co-incubation with BOEC pretreated with $100 \mathrm{ng} / \mathrm{mL}$ of E2 $(P<0.01$; Fig. $4 \mathrm{~A})$. However, the pretreatment of BOEC with $\mathrm{P} 4$ had no effect on sperm binding after 10 and 60 min of co-incubation (Fig. 4B).

\section{P4-induced sperm release from BOEC}

In Experiment 2, heparin at $100 \mu \mathrm{g} / \mathrm{mL}$ induced the release of almost all spermatozoa from BOEC within $60 \mathrm{~min}$ (Fig. 5). Furthermore, 60-min treatments with P4 at the three concentrations tested induced a significant decrease by $32-42 \%$ in the number of bound spermatozoa (Fig. 5B). This sperm-releasing effect of P4 was more significant at the dose of $1000 \mathrm{ng} / \mathrm{mL}(P<0.01)$ than at 10 and $100 \mathrm{ng} / \mathrm{mL}(P<0.05)$. Conversely, E2 at the three concentrations tested did not have any effect on sperm release (Fig. 5A).

Experiment 3 showed that the sperm-releasing effect of P4 at the physiological concentration of $100 \mathrm{ng} / \mathrm{mL}$ was still evidenced after a pretreatment of BOEC with a physiological concentration (100 pg/mL) of E2 (Fig. 6).

\section{E2 inhibited the releasing effect of P4 on bound sperm}

In Experiment 4, P4 at $100 \mathrm{ng} / \mathrm{mL}$ induced a significant decrease by $47 \%$ in the number of bound sperm compared with the control group, as previously shown
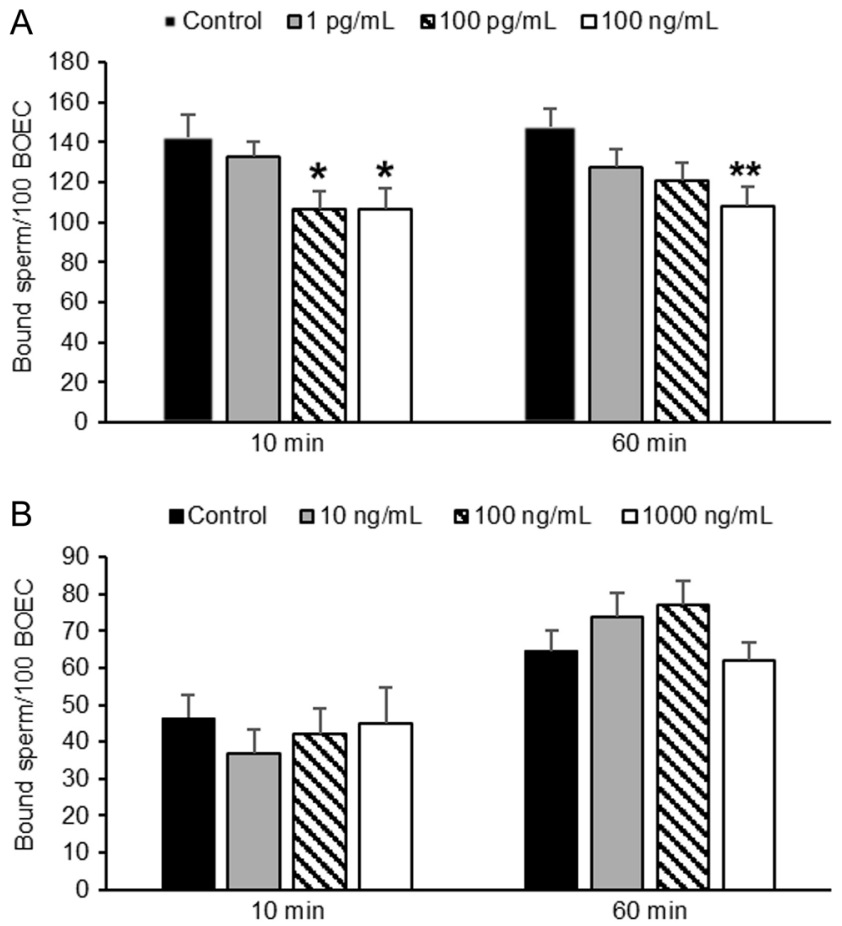

Figure 4 Effects of a pretreatment of BOEC with 17 $\beta$-estradiol (E2) and progesterone (P4) on sperm binding. BOEC were pretreated with E2 at $1,100 \mathrm{pg} / \mathrm{mL}$ or $100 \mathrm{ng} / \mathrm{mL}$ (A) or with $10,100,1000 \mathrm{ng} / \mathrm{mL}$ of P4 (B) during $18 \mathrm{~h}$ before co-incubation with spermatozoa for 10 or 60 min (Experiment 1). Control cells were pretreated with vehicle. Results are expressed as mean \pm S.E.M. of bound spermatozoa per 100 BOEC. ${ }^{* *} P<0.01 ; * P<0.05$. 

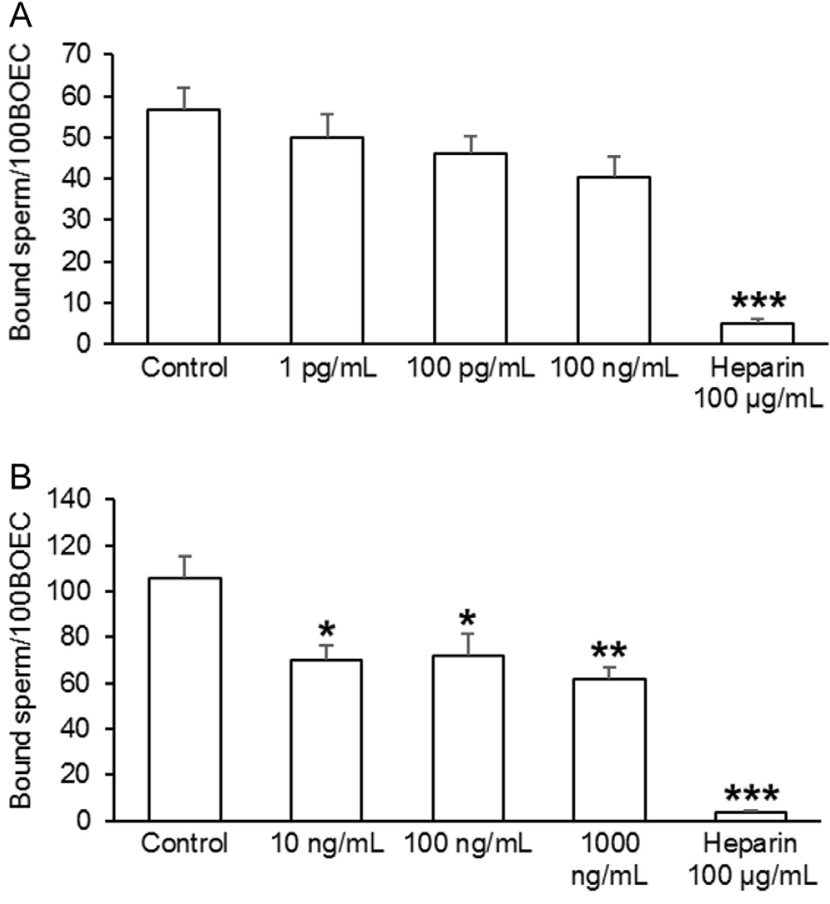

Figure 5 Effects of treatments with $17 \beta$-estradiol (E2) or progesterone (P4) on sperm release from BOEC. After 30 min of sperm-BOEC CO-incubation, CO-cultures were treated with $\mathrm{E} 2$ at $1,100 \mathrm{pg} / \mathrm{mL}$ or $100 \mathrm{ng} / \mathrm{mL}$ (A), P4 at 10, 100 or $1000 \mathrm{ng} / \mathrm{mL}$ (B) or heparin at $100 \mu \mathrm{g} / \mathrm{mL}$ as a positive control for $60 \mathrm{~min}$ (Experiment 2). Controls were treated with vehicle. Results are expressed as mean \pm S.E.M. of bound spermatozoa per 100 BOEC. ${ }^{* * *} P<0.001 ;{ }^{* *} P<0.01 ;{ }^{*} P<0.05$.

$(P<0.001$; Fig. 7). When $\mathrm{P} 4$ at the same concentration was added with $1 \mathrm{pg} / \mathrm{mL}$ of $\mathrm{E} 2$, a less but still significant decrease (by $34 \% ; P<0.01$ ) in the number of bound sperm was observed. However, when P4 was added with $100 \mathrm{pg} / \mathrm{mL}$ or $100 \mathrm{ng} / \mathrm{mL}$ of E2, numbers of bound sperm remained comparable to that in the control group. Thus,

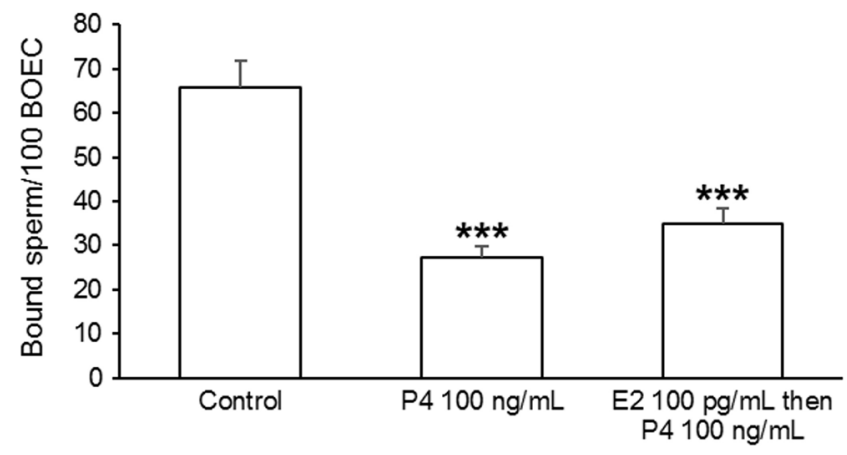

Figure 6 Effect of a pretreatment of BOEC with $17 \beta$-estradiol (E2) on the releasing effect of $\mathrm{P} 4$ on bound sperm. BOEC were pretreated with $\mathrm{E} 2$ at $100 \mathrm{pg} / \mathrm{mL}$ for $18 \mathrm{~h}$ before being co-incubated with spermatozoa during $30 \mathrm{~min}$. Co-cultures were then treated with or progesterone (P4) at $100 \mathrm{ng} / \mathrm{mL}$ for $60 \mathrm{~min}$ (Experiment 3). Controls were treated with vehicle. Results are expressed as mean \pm S.E.M. of bound spermatozoa per 100 BOEC. ${ }^{* * *} P<0.001$.

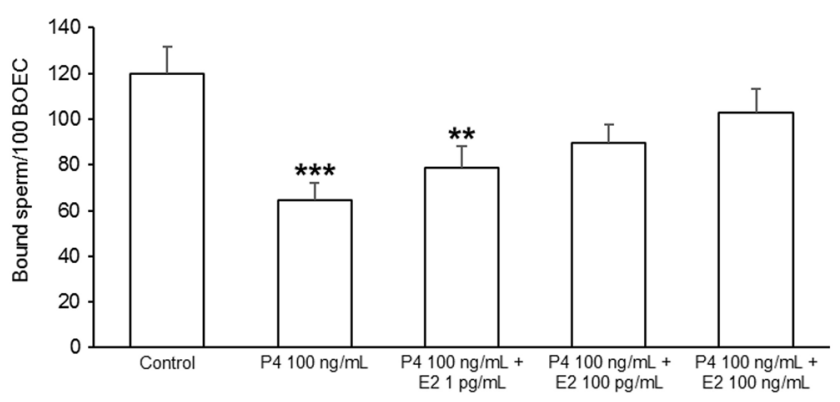

Figure 7 Effect of $17 \beta$-estradiol (E2) on the releasing effect of progesterone (P4) on bound sperm. After $30 \mathrm{~min}$ of sperm-BOEC co-incubation, co-cultures were treated with $\mathrm{P} 4$ at $100 \mathrm{ng} / \mathrm{mL}$ or $\mathrm{P} 4$ at $100 \mathrm{ng} / \mathrm{mL}+\mathrm{E} 2$ at $1,100 \mathrm{pg} / \mathrm{mL}$ or $100 \mathrm{ng} / \mathrm{mL}$ for $60 \mathrm{~min}$ (Experiment 4). Controls were treated with vehicle. Results are expressed as mean \pm S.E.M. of bound spermatozoa per 100 BOEC. *** $P<0.001 ; * * P<0.01$.

E2 inhibited the P4-induced release of bound sperm from BOEC in a dose-dependent manner.

\section{Sperm bound to BOEC then released by $\mathrm{P} 4$ displayed higher fertilizing ability and blastocyst yield}

In Experiment 5, the cleavage rate obtained at Day 2 after insemination with P4-released spermatozoa from BOEC (P4-BOEC-spz; 86.7\%) was significantly higher than that obtained in the control group $(74.1 \%$; Table 1). However, the cleavage rates of spermatozoa unbound after co-incubation with BOEC (BOEC-spz) and spermatozoa treated with P4 alone (P4-spz) did not differ from that in the control group. Furthermore, at Days 7 and 8 post insemination, the rates of blastocyst obtained with P4-BOEC-spz were higher than those in the control group $(43.3 \%$ vs $30.5 \%$ and $40.4 \%$ vs $27.7 \%$ at Days 7 and 8 , respectively). When calculated as percentages of cleaved embryos, the blastocyst rate obtained with P4-BOEC-spz remained significantly higher than that in the control group at Day 8 post insemination (45.9 vs $33.3 \%$; Table 1 ).

Table 1 Cleavage rates at Day 2 and blastocyst rates at Days 7 and 8 after insemination of bovine in vitro-matured oocytes with control spermatozoa, spermatozoa treated with $100 \mathrm{ng} / \mathrm{mL}$ of progesterone (P4-spz), unbound spermatozoa after co-incubation with BOEC (BOEC-spz) or spermatozoa bound to BOEC then released by a treatment with $100 \mathrm{ng} / \mathrm{mL}$ of progesterone (BOEC-P4-spz).

\begin{tabular}{|c|c|c|c|c|c|c|}
\hline \multirow[b]{3}{*}{ Treatment } & \multirow[b]{3}{*}{$n$} & $\begin{array}{c}\text { Cleavage } \\
\text { rate }\end{array}$ & \multicolumn{4}{|c|}{ Blastocyst yield } \\
\hline & & Day 2 pi & \multicolumn{2}{|c|}{ Day 7 pi } & \multicolumn{2}{|c|}{ Day 8 pi } \\
\hline & & $\%$ & $\% *$ & $\% * *$ & $\% *$ & $\% * *$ \\
\hline Control & 391 & $74.1^{\mathrm{a}}$ & $30.5^{\mathrm{a}}$ & $37.9^{\mathrm{a}}$ & $27.7^{\mathrm{a}}$ & $33.3^{\mathrm{a}}$ \\
\hline P4-spz & 130 & 77.7 & 41.5 & $53.5^{\mathrm{b}}$ & 30.8 & 39.6 \\
\hline BOEC-spz & 118 & 83.1 & 41.5 & 50.0 & 34.7 & 41.8 \\
\hline BOEC-P4-spz & 211 & $86.7^{b}$ & $43.3^{b}$ & 49.2 & $40.4^{b}$ & $45.9^{b}$ \\
\hline
\end{tabular}

Different superscripts within columns indicate statistical differences $(P<0.05$, chi-squared test).

$n$, total number of cumulus-oocyte complexes (COCs); $* \%$, of total COCs; $* * \%$, of cleaved embryos. 


\section{Discussion}

In the cow, after insemination, a sperm reservoir is formed in the oviducts, allowing the storage and then the progressive release of selected spermatozoa toward the ovulated oocyte. However, the endocrine regulation of these events has been poorly investigated. The main findings of this in vitro study are that: (1) a pretreatment of BOEC with E2 at physiological concentrations slightly modified the kinetics of sperm binding; (2) P4 triggered the release of bound spermatozoa from BOEC; (3) E2 inhibited the releasing effect of P4 on bound sperm in a dose-dependent manner; (4) the sequential binding to the BOEC followed by $\mathrm{P} 4$-induced release selected a sperm subpopulation with higher fertilizing and developmental ability than controls. These results support the hypothesis that dynamic changes in steroid hormone concentrations around the time of ovulation regulate the formation of the sperm reservoir and the subsequent delivery of capacitated spermatozoa to the site of fertilization.

The in vitro model of confluent BOEC monolayers used in the present study was previously shown to generate a typical display of epithelial cell morphology and cytokeratin expression (Van Lagendonckt et al. 1995) and to be able to sustain early bovine embryo development and quality (Cordova et al. 2014, SchmaltzPanneau et al. 2015). The same model used in the present study allowed a reliable and reproducible visualization and counting of bound spermatozoa, as previously described in numerous studies on sperm-oviduct interactions (Pollard et al. 1991, Gualtieri \& Talevi 2000, 2003, Talevi \& Gualtieri 2001, Osycka-Salut et al. 2017). In order to further characterize our in vitro model, observations of sperm-oviduct interactions after 30 min of co-incubation were carried out by CSTEM. The advantage of the recent correlative S.E.M./TEM method, applied for the first time on sperm-BOEC co-culture, is to combine in the same interacting cells the visualization of cell surface and intracellular ultrastructure (BurlaudGaillard et al. 2014). 'Transmission electron microscopy images showed that cell microvilli and cilia interacted either with the whole bottom surface or only with the acrosomal region of sperm cells despite very similar scanning electron microscopy pictures obtained at the cell surface, showing acrosome-intact sperm heads bound to BOEC. These pictures were in accord with earlier studies in the same species (Pollard et al. 1991, Suzuki \& Foote 1995, Gualtieri \& Talevi 2000). In vivo, the sperm reservoir is mainly located in the distal part of the oviduct, namely the isthmus (Hunter \& Wilmut 1984). However, ex vivo, bull spermatozoa bind in similar patterns and in equivalent numbers to explants from the ampulla and isthmus (Lefebvre et al. 1995, Sostaric et al. 2008). Furthermore, the direct video recording of mouse sperm during their migration toward the oocyte showed that spermatozoa detach and attach again several times to the oviduct epithelium, including the ampulla (Chang \& Suarez 2012). Thus, as a first attempt to decipher the potential roles played by P4 and E2 on sperm-oviduct interactions, this simple and valuable bioassay system with BOEC from the whole oviduct was used.

It is widely accepted that the ovarian steroid hormones $\mathrm{P} 4$ and E2 are major regulators of the oviductal epithelium, acting through genomic and non-genomic pathways (Hunter 2012). We reported important fluctuations in the topical concentrations of P4 and E2 in the bovine oviductal fluid between the pre- and the postovulatory stages of the estrous cycle, in particular in the side of ovulation (Lamy et al. 2016). According to these data, concentrations of $100 \mathrm{pg} / \mathrm{mL}$ of E2 and of 10 and $100 \mathrm{ng} / \mathrm{mL}$ of P4 were considered to be representative of concentrations the apical surface of the bovine oviduct epithelium is exposed to in vivo around the time of ovulation. Overall, the results of Experiment 1 showed that the pretreatment of BOEC with physiological concentrations of E2 and P4 did not dramatically alter their ability to bind spermatozoa. Indeed, except with the supraphysiological concentration of $100 \mathrm{ng} / \mathrm{mL}$ of E2, the density of bound spermatozoa was the same in control and pretreated cells after $60 \mathrm{~min}$ of co-incubation. This is in accord with previous results showing similar numbers of spermatozoa bound to bovine oviduct explants collected at different stages of the estrous cycle in the cow (Lefebvre et al. 1995). Accordingly, human oviduct explants incubated overnight with physiological concentrations of E2 (Baillie et al. 1997) and porcine oviduct epithelial vesicles pretreated for $48 \mathrm{~h}$ with $100 \mathrm{ng} / \mathrm{mL}$ of E2 (Bureau et al. 2002) displayed similar sperm-binding capacities compared with non-treated samples after 30-60 min of co-incubation. In the present study, a pretreatment of BOEC with E2 slightly delayed the kinetics of sperm binding as less spermatozoa bound to treated cells (with $100 \mathrm{pg} / \mathrm{mL}$ and $100 \mathrm{ng} / \mathrm{mL}$ of E2) than to control cells after $10 \mathrm{~min}$ of co-incubation. To our knowledge, the evaluation of sperm-binding capacity within such a short interval of time after sperm co-incubation has not been reported previously. The E2 pretreatment might have modified the cell-surface proteins involved in sperm binding and modulated in this way the kinetics of sperm binding to BOEC. Nevertheless, the effect of pretreatment with $100 \mathrm{pg} /$ $\mathrm{mL}$ of $\mathrm{E} 2$ on BOEC binding capacity was slight $(25 \%$ decrease in numbers of bound sperm) and short lasting.

Near the time of ovulation, the sperm detachment from the oviduct epithelium and progressive migration toward the oocyte represent crucial steps for a successful fertilization. The sperm-releasing process occurs in vivo in parallel with an increase in topical P4 concentrations (Lamy et al. 2016). In the present study, P4 from 10 to $1000 \mathrm{ng} / \mathrm{mL}$ in concentration triggered sperm release from BOEC within $60 \mathrm{~min}$. However, the effect of $100 \mu \mathrm{g} / \mathrm{mL}$ of heparin on sperm release was always stronger than that of P4: $>90 \%$ vs $32-47 \%$ 
of spermatozoa detached from BOEC after exposure to heparin and P4, respectively. A long (at least $4 \mathrm{~h}$ ) exposure to heparin at the optimal concentration of $5-10 \mu \mathrm{g} / \mathrm{mL}$ has been known for a long time to induce sperm capacitation in the bovine (Parrish et al. 1988). At the higher concentration of $100 \mu \mathrm{g} / \mathrm{mL}$, heparin was reported to be a rapid inducer of sperm release from OEC in the bovine (Talevi \& Gualtieri 2001, 2010). However, the release of sperm cells from the reservoir is a gradual process taking place over several hours (Chang \& Suarez 2012): the detachment of all spermatozoa within one hour as evidenced with $100 \mu \mathrm{g} / \mathrm{mL}$ heparin is unlikely to happen in vivo. The sperm-releasing effects of P4 in the present study are in accord with previous in vivo results in the porcine in which an injection of P4 beneath the serosa or within the lumen of the tubal isthmus led to an increase in the number of spermatozoa around oocytes and polyspermy (Hunter 1972, 2008, Hunter et al. 1999). Taking into account the inhibitory effects of P4 on oviduct smooth muscle contractions and mucosa edema, this higher number of spermatozoa around oocytes was interpreted as a consequence of reduced physical barriers to sperm progression toward the site of fertilization (Suarez 2016). However, our results support a direct action of $\mathrm{P} 4$ on spermatozoa or simultaneously on both sperm and oviduct epithelial cell surface to trigger sperm release. It is likely that hyperactivation plays an important role in the release of spermatozoa from the oviduct epithelium in mammals (Demott \& Suarez 1992, Chang \& Suarez 2012, Ardon et al. 2016). Spermatozoa with hyperactivated motility were observed while they detached from bovine mucosal folds of oviduct epithelium in vitro (Ardon et al. 2016) and from the epithelium in entire oviducts retrieved from mouse females just after mating (Demott \& Suarez 1992, Chang \& Suarez 2012). Hyperactivated spermatozoa display asymmetrical, high-amplitude flagellar movements (Yanagimachi 1970) that are not only important for sperm release but also essential for the penetration of the cumulus oophorus and the zona pellucida surrounding the oocyte (Hung \& Suarez 2010). Moreover, there is evidence that P4 induces or enhances hyperactivated motility in human and hamster spermatozoa (Sueldo et al. 1993, Noguchi et al. 2008), probably mediated through an influx of calcium into sperm cells (Publicover et al. 2007). Thus, it is likely that the sperm detachment in the present study was mediated by a P4-triggered hyperactivated motility on bound spermatozoa. However, as evoked above for E2, a modification by $\mathrm{P} 4$ of the cell-surface proteins that would reduce the binding affinity of spermatozoa cannot be excluded. The expression of nuclear as well as membrane P4 receptor membrane components (PGRMC) 1 and 2 were previously shown in BOEC (Saint-Dizier et al. 2012). Taking into account the relatively short time $(60 \mathrm{~min})$ during which sperm-BOEC co-cultures were exposed to P4, these cell-surface modifications, if they occur, would be mediated through the latter by non-genomic mechanisms.

In the present study, E2 had no effect on sperm release by itself, as shown in Experiment 2. A 18-h pretreatment of BOEC with $100 \mathrm{pg} / \mathrm{mL}$ of E2, that was applied to mimic the peri-ovulatory action of E2 on oviductal cells, did not affect the releasing action of P4 on bound sperm, as shown in Experiment 3. However, in Experiment 4, E2 acted as a suppressor of the sperm-releasing effect of P4 when added simultaneously with this hormone. This effect of E2 was dose dependent: the releasing effect of $100 \mathrm{ng} / \mathrm{mL}$ of P4 was suppressed by $\geq 100 \mathrm{pg} / \mathrm{mL}$ but not with $1 \mathrm{pg} / \mathrm{mL}$ of E2. Similarly in hamster spermatozoa, E2 did not affect sperm motility by itself but suppressed P4-stimulated hyperactivation in a concentrationdependent manner: this effect was mediated by the inhibition of tyrosine phosphorylation through nongenomic pathways (Fujinoki 2010). Taken together, it could be hypothesized that E2 prevented the P4-induced sperm release from BOEC above $100 \mathrm{pg} / \mathrm{mL}$ by a dosedependent inhibition of sperm hyperactivation. Further work examining the sperm motility and intracellular physiology at the time of addition of P4 or P4 + E2 would be necessary to support this hypothesis. Furthermore, diethylstilbestrol, an estrogen-like product, has been previously shown to disrupt the effects of P4 and E2 on sperm hyperactivation (Fujinoki 2014): it would be of interest to examine the effect of estrogen-like products on the regulation of sperm release by $\mathrm{P} 4$ and $\mathrm{E} 2$ in the bovine.

It is noteworthy that the concentration at which E2 exerted its inhibitory effect was very close to the concentration $(118 \mathrm{pg} / \mathrm{mL})$ that was previously reported in the bovine tubal fluid after ovulation (Lamy et al. 2016), at which time sperm release is supposed to happen. Nevertheless, this value is an average concentration measured in pools of fluids collected between Days 1-5 of the estrous cycle (Lamy et al. 2016) and may not reflect the fine-tuned hourly changes in the P4:E2 balance that probably occur within the oviduct around the time of ovulation. The postovulatory decline in topical E2 might lengthen the release of spermatozoa from the sperm reservoir and thus prolong the fertilization time window in vivo.

Finally, in order to better characterize the P4-released spermatozoa from BOEC, in vitro fertilization experiments were undertaken. The results showed that the binding to the BOEC followed by the P4-induced release from BOEC enhanced the ability of spermatozoa to fertilize oocytes compared with spermatozoa in the control group. This is in accord with previous results showing that the binding to OEC achieves the selection of a sperm subpopulation with intact acrosome and normal morphology (Thomas et al. 1994, Lefebvre \& Suarez 1996, Ellington et al. 1999a, Gualtieri \& Talevi 2000). These results also agree with a previous study in which bull spermatozoa retrieved from 
BOEC co-culture with an heparin treatment displayed enhanced ability to adhere to the zona pellucida and to fertilize oocytes compared with unbound sperm (Gualtieri \& Talevi 2003). In addition to its role on sperm hyperactivation, stimulating roles of $\mathrm{P} 4$ were reported on mammalian sperm capacitation, acrosome reaction and chemical guidance (Baldi et al. 2009, Guidobaldi et al. 2012, Fujinoki et al. 2016). The exposition to P4 alone in the absence of BOEC did not have any significant effect on sperm fertilizing ability compared with the control group. However, no difference in the cleavage rates was either seen between spermatozoa exposed to P4 alone and those previously bound to BOEC and released by $\mathrm{P} 4$. It could be hypothesized that spermatozoa with high fertilizing competence were selected by a double check point: a first selection was achieved by the adhesion to BOEC, then the ability to respond to the $\mathrm{P} 4$ signal by detaching from BOEC, displayed by $32-47 \%$ of spermatozoa in Experiments $2-4$, represented a second selection step. The binding to BOEC followed by the P4-induced release improved not only the ability of sperm to bind and penetrate oocytes, reflected by the cleavage rate, but also improved the embryo development up to the blastocyst stage at Day 8 compared with the control group. It is well established that pretreatment or preparation allowing the selection of a sperm subpopulation with high motility, membrane and/or DNA integrity support embryo development and blastocyst yield after IVF in the bovine (Jaakma et al. 1997, Gualtieri et al. 2014, Pang et al. 2016). Our results support the hypothesis that the ability to bind to BOEC and to be released by P4 is a highly selective process for bull spermatozoa. A previous study reported a positive association between the ability of sperm to bind OEC in vitro and the in vivo fertility in bulls (De pauw et al. 2002). Our in vitro system may be useful to determine whether the sequential binding to the BOEC followed by the P4-induced release from the BOEC could be of help in better predicting the in vivo fertility of a given bull.

\section{Conclusion}

In conclusion, we characterized some crucial roles played by the steroid hormones P4 and E2 in the regulation of sperm-oviduct interactions in a bovine in vitro model. Progesterone triggers sperm release from the oviduct epithelium and selects in this way a subpopulation of spermatozoa with high fertilizing competence, while E2 inhibits P4-induced sperm release. Further work is now needed to clarify how the dynamic topical E2:P4 balance in the periovulatory period orchestrates sperm attachment and release in vivo and to identify the specific mechanisms of action of these hormones on sperm physiology and/or on modulation of molecules on the surface of tubal cells.

\section{Declaration of interest}

The authors declare that there is no conflict of interest that could be perceived as prejudicing the impartiality of the research reported.

\section{Funding}

The research leading to these results has received funding from the European Union's Seventh Framework Program for research, technological development and demonstration under grant agreement no. 312097 FECUND.

\section{Acknowledgements}

Authors are grateful to Marc Chodkiewicz for reviewing the manuscript.

\section{References}

Ardon F, Markello RD, Hu L, Deutsch ZI, Tung CK, Wu M \& Suarez SS 2016 Dynamics of bovine sperm interaction with epithelium differ between oviductal isthmus and ampulla. Biology of Reproduction 95 90. (doi:10.1095/biolreprod.116.140632)

Baillie HS, Pacey AA, Warren MA, Scudamore IW \& Barratt CIR 1997 Greater numbers of human spermatozoa associate with endosalpingeal cells derived from the isthmus compared with those from the ampulla. Human Reproduction 12 1985-1992. (doi:10.1093/humrep/12.9.1985)

Baldi E, Luconi M, Muratori M, Marchiani S, Tamburrino L \& Forti G 2009 Nongenomic activation of spermatozoa by steroid hormones: facts and fictions. Molecular and Cellular Endocrinology 308 39-46. (doi:10.1016/j.mce.2009.02.006)

Brussow KP, Ratky J \& Rodriguez-Martinez H 2008 Fertilization and early embryonic development in the porcine fallopian tube. Reproduction in Domestic Animals 43 (Supplement 2) 245-251. (doi:10.1111/j.14390531.2008.01169.x)

Bureau M, Bailey JL \& Sirard MA 2002 Binding regulation of porcine spermatozoa to oviductal vesicles in vitro. Journal of Andrology 23188 193. (doi:10.1002/j.1939-4640.2002.tb02614.x)

Burlaud-Gaillard J, Sellin C, Georgeault S, Uzbekov R, Lebos C, Guillaume JM \& Roingeard P 2014 Correlative scanning-transmission electron microscopy reveals that a chimeric flavivirus is released as individual particles in secretory vesicles. PLOS ONE 9 e93573. (doi:10.1371/ journal.pone.0093573)

Chang H \& Suarez SS 2012 Unexpected flagellar movement patterns and epithelial binding behavior of mouse sperm in the oviduct. Biology of Reproduction 86 141-148. (doi:10.1093/biolreprod/87.s1.141)

Cordova A, Perreau C, Uzbekova S, Ponsart C, Locatelli Y \& Mermillod P 2014 Development rate and gene expression of IVP bovine embryos cocultured with bovine oviduct epithelial cells at early or late stage of preimplantation development. Theriogenology 81 1163-1173. (doi:10.1016/j.theriogenology.2014.01.012)

De pauw I, Van Soom A, Laevens H, Verberckmoes S \& de Kruif A 2002 Sperm binding to epithelial oviduct explants in bulls with different nonreturn rates investigated with a new in vitro model. Biology of Reproduction 67 1073-1079. (doi:10.1095/biolreprod67.4.1073)

Demott RP \& Suarez SS 1992 Hyperactivated sperm progress in the mouse oviduct. Biology of Reproduction 46 779-785. (doi:10.1095/ biolreprod46.5.779)

Ellington JE, Padilla AW, Vredenburgh WL, Dougherty EP \& Foote RH 1991 Behavior of bull spermatozoa in bovine uterine tube epithelial cell co-culture: an in vitro model for studying the cell interactions of reproduction. Theriogenology 35 977-989. (doi:10.1016/0093691X(91)90308-Z)

Ellington JE, Evenson DP, Wright RW Jr, Jones AE, Schneider CS, Hiss GA \& Brisbois RS 1999a Higher-quality human sperm in a sample selectively 
attach to oviduct (fallopian tube) epithelial cells in vitro. Fertility and Sterility 71 924-929. (doi:10.1016/S0015-0282(99)00095-3)

Ellington JE, Samper JC, Jones AE, Oliver SA, Burnett KM \& Wright RW $1999 \mathrm{~b}$ In vitro interactions of cryopreserved stallion spermatozoa and oviduct (uterine tube) epithelial cells or their secretory products Animal Reproduction Science 56 51-65. (doi:10.1016/S03784320(99)00030-5)

Fujinoki M 2010 Suppression of progesterone-enhanced hyperactivation in hamster spermatozoa by estrogen. Reproduction 140 453-464. (doi:10.1530/REP-10-0168)

Fujinoki M 2014 Regulation and disruption of hamster sperm hyperactivation by progesterone, 17 beta-estradiol and diethylstilbestrol. Reproductive Medicine and Biology 13 143-152. (doi:10.1007/s12522013-0175-8)

Fujinoki M, Takei GL \& Kon H 2016 Non-genomic regulation and disruption of spermatozoal in vitro hyperactivation by oviductal hormones. Journal of Physiological Sciences 66 207-212. (doi:10.1007/s12576-0150419-y)

Gervasi MG, Rapanelli M, Ribeiro ML, Farina M, Billi S, Franchi AM \& Perez Martinez S 2009 The endocannabinoid system in bull sperm and bovine oviductal epithelium: role of anandamide in sperm-oviduct interaction. Reproduction 137 403-414. (doi:10.1530/REP-08-0204)

Glencross RG, Munro IB, Senior BE \& Pope GS 1973 Concentrations of oestradiol-17 $\beta$, oestrone, and progesterone in jugular venous plasma of cows during the oestrous cycle and in early pregnancy. Acta Endocrinologica 73 374-384. (doi:10.1530/acta.0.0730374)

Gualtieri R \& Talevi R 2000 In vitro cultured bovine oviductal cells bind acrosome-intact sperm and retain this ability upon sperm release. Biology of Reproduction 62 1754-1762. (doi:10.1095/ biolreprod62.6.1754)

Gualtieri R \& Talevi R 2003 Selection of highly fertilization-competent bovine spermatozoa through adhesion to the Fallopian tube epithelium in vitro. Reproduction 125 251-258. (doi:10.1530/ rep.0.1250251)

Gualtieri R, Barbato V, Fiorentino I, Braun S, Rizos D, Longobardi S \& Talevi R 2014 Treatment with zinc, d-aspartate, and coenzyme Q10 protects bull sperm against damage and improves their ability to support embryo development. Theriogenology 82 592-598. (doi:10.1016/j. theriogenology.2014.05.028)

Guidobaldi HA, Teves ME, Unates DR \& Giojalas LC 2012 Sperm transport and retention at the fertilization site is orchestrated by a chemical guidance and oviduct movement. Reproduction 143 587-596. (doi:10.1530/REP-11-0478)

Holm P, Booth PJ, Schmidt MH, Greve T \& Callesen H 1999 High bovine blastocyst development in a static in vitro production system using SOFaa medium supplemented with sodium citrate and myo-inositol with or without serum-proteins. Theriogenology 52 683-700. (doi:10.1016/ S0093-691X(99)00162-4)

Hung PH \& Suarez SS 2010 Regulation of sperm storage and movement in the ruminant oviduct. Society of Reproduction and Fertility Supplement 67 257-266. (doi:10.7313/upo9781907284991.022)

Hunter RH 1972 Local action of progesterone leading to polyspermic fertilization in pigs. Journal of Reproduction and Fertility 31 433-444. (doi:10.1530/jrf.0.0310433)

Hunter RH 2008 Sperm release from oviduct epithelial binding is controlled hormonally by peri-ovulatory graafian follicles. Molecular Reproduction and Development 75 167-174. (doi:10.1002/mrd.20776)

Hunter RH 2012 Components of oviduct physiology in eutherian mammals. Biological Reviews of the Cambridge Philosophical Society 287 244-255. (doi:10.1111/j.1469-185X.2011.00196.x)

Hunter RH \& Wilmut I 1984 Sperm transport in the cow: peri-ovulatory redistribution of viable cells within the oviduct. Reproduction Nutrition Development 24 597-608. (doi:10.1051/rnd:19840508)

Hunter RHF, Petersen HH \& Greve T 1999 Ovarian follicular fluid, progesterone and $\mathrm{Ca} 2+$ ion influences on sperm release from the Fallopian tube reservoir. Molecular Reproduction and Development 54 283-291. (doi:10.1002/(SICI)1098-2795(199911)54:3<283::AIDMRD9>3.0.CO;2-T)

Ireland J, Murphee RL \& Coulson PB 1980 Accuracy of predicting stages of bovine estrous cycle by gross appearance of the corpus luteum. Journal of Dairy Science 63 155-160. (doi:10.3168/jds.S00220302(80)82901-8)
Jaakma U, Zhang BR, Larsson B, Niwa K \& Rodriguez-Martinez H 1997 Effects of sperm treatments on the in vitro development of bovine oocytes in semidefined and defined media. Theriogenology 48 711-720. (doi:10.1016/S0093-691X(97)00295-1)

Lamy J, Liere P, Pianos A, Aprahamian F, Mermillod P \& Saint-Dizier M 2016 Steroid hormones in bovine oviductal fluid during the estrous cycle. Theriogenology 86 1409-1420. (doi:10.1016/j. theriogenology.2016.04.086)

Lefebvre R \& Suarez SS 1996 Effect of capacitation on bull sperm binding to homologous oviductal epithelium. Biology of Reproduction $\mathbf{5 4}$ 575-582. (doi:10.1095/biolreprod54.3.575)

Lefebvre R, Chenoweth PJ, Drost M, Leclear CT, MacCubbin M, Dutton JT \& Suarez SS 1995 Characterization of oviductal sperm reservoir in cattle. Biology of Reproduction 53 1066-1074. (doi:10.1095/ biolreprod53.5.1066)

Noguchi T, Fujinoki M, Kitazawa M \& Inaba N 2008 Regulation of hyperactivation of hamster spermatozoa by progesterone. Reproductive Medicine and Biology 7 63-74. (doi:10.1111/j.14470578.2008.00202.x

Osycka-Salut CE, Castellano L, Fornes D, Beltrame JS, Alonso C, Jawerbaum A, Franchi A, Diaz ES \& Perez Martinez S 2017 Fibronectin from oviductal cells fluctuates during the estrous cycle and contributes to sperm-oviduct interaction in cattle. Journal of Cellular Biochemistry Epub. (doi:10.1002/jcb.26067)

Pang YW, Sun YQ, Jiang XL, Huang ZQ, Zhao SJ, Du WH, Hao HS, Zhao XM \& Zhu HB 2016 Protective effects of melatonin on bovine sperm characteristics and subsequent in vitro embryo development. Molecular Reproduction and Development 83 993-1002. (doi:10.1002/ mrd.22742)

Parrish JJ, Susko-Parrish J, Winer MA \& First NL 1988 Capacitation of bovine sperm by heparin. Biology of Reproduction 38 1171-1180. (doi:10.1095/biolreprod38.5.1171)

Pollard JW, Plante C, King WA, Hansen PJ, Betteridge KJ \& Suarez SS 1991 Fertilizing capacity of bovine sperm may be maintained by binding to oviductal epithelial cells. Biology of Reproduction 44 102-107. (doi:10.1095/biolreprod44.1.102)

Publicover S, Harper CV \& Barratt C 2007 [Ca2+]i signalling in sperm making the most of what you've got. Nature Cell Biology 9 235-242. (doi:10.1038/ncb0307-235)

Saint-Dizier M, Sandra O, Ployart S, Chebrout M \& Constant F 2012 Expression of nuclear progesterone receptor and progesterone receptor membrane components 1 and 2 in the oviduct of cyclic and pregnant cows during the post-ovulation period. Reproductive Biology and Endocrinology 10 76. (doi:10.1186/1477-7827-10-76)

Schindelin J, Arganda-Carreras I, Frise E, Kaynig V, Longair M, Pietzsch T, Preibisch S, Rueden C, Saalfeld S, Schmid B et al. 2012 Fiji: an open-source platform for biological-image analysis. Nature Methods $\mathbf{9}$ 676-682. (doi:10.1038/nmeth.2019)

Schmaltz-Panneau B, Locatelli Y, Uzbekova S, Perreau C \& Mermillod P 2015 Bovine oviduct epithelial cells dedifferentiate partly in culture, while maintaining their ability to improve early embryo development rate and quality. Reproduction in Domestic Animals 50 719-729. (doi:10.1111/rda.12556)

Sostaric E, Dieleman SJ, van de Lest CH, Colenbrander B, Vos PL, GarciaGil N \& Gadella BM 2008 Sperm binding properties and secretory activity of the bovine oviduct immediately before and after ovulation. Molecular Reproduction and Development 75 60-74. (doi:10.1002/mrd.20766)

Suarez SS 2016 Mammalian sperm interactions with the female reproductive tract. Cell Tissue Research 363 185-194. (doi:10.1007/ s00441-015-2244-2)

Suarez S, Redfern K, Raynor P, Martin F \& Phillips DM 1991 Attachment of boar sperm to mucosal explants of oviduct in vitro: possible role in formation of a sperm reservoir. Biology of Reproduction 44 998-1004. (doi:10.1095/biolreprod44.6.998)

Sueldo CE, Oehninger S, Subias E, Mahony M, Alexander NJ, Burkman LJ \& Acosta AA 1993 Effect of progesterone on human zona pellucida sperm binding and oocyte penetrating capacity. Fertility and Sterility $\mathbf{6 0}$ 137-140. (doi:10.1016/S0015-0282(16)56051-8)

Suzuki H \& Foote RH 1995 Bovine oviductal epithelial cells (BOEC) and oviducts: I. For embryo culture. II. Using SEM for studying interactions with spermatozoa. Microscopy Research and Technique 31 519-530. (doi:10.1002/jemt.1070310608) 
Talevi R \& Gualtieri R 2001 Sulfated glycoconjugates are powerful modulators of bovine sperm adhesion and release from the oviductal epithelium in vitro. Biology of Reproduction 64 491-498. (doi:10.1095/ biolreprod64.2.491)

Talevi R \& Gualtieri R 2010 Molecules involved in sperm-oviduct adhesion and release. Theriogenology 73 796-801. (doi:10.1016/j. theriogenology.2009.07.005)

Thomas PGA, Ball BA \& Brinsko SP 1994 Interaction of equine spermatozoa with oviduct epithelial cell explants is affected by estrous cycle and anatomic origin of explant. Biology of Reproduction $51222-228$.

Van Lagendonckt A, Vansteenbruge A, Dessy-Doizé C, Flechon J-E, Charpigny G, Mermillod P, Massip A \& Dessy F 1995 Characterization of bovine oviduct epithelial cell monolayers cultured under serum-free conditions. In Vitro Cellular and Developmental Biology 31 664-670. (doi:10.1007/BF02634087)

Vigil P, Toro A \& Godoy A 2008 Physiological action of oestradiol on the acrosome reaction in human spermatozoa. Andrologia 40 146-151. (doi:10.1111/j.1439-0272.2007.00814.x)
Waberski D, Magnus F, Mendonca Ferreira F, Petrunkina AM, Weitze KF \& Topfer-Petersen E 2005 Importance of sperm-binding assays for fertility prognosis of porcine spermatozoa. Theriogenology 63 470-484. (doi:10.1016/j.theriogenology.2004.09.025)

Yanagimachi R 1970 The movement of golden hamster spermatozoa before and after capacitation. Journal of Reproduction and Fertility 23 193-196. (doi:10.1530/jrf.0.0230193)

Received 31 May 2017

First decision 22 June 2017

Revised manuscript received 26 June 2017

Accepted 20 July 2017 